\title{
Rilkes Beziehungen zu Spanien: wie sie war, wie sie hätte sein können und wie sie ist
}

\author{
(Festvortrag in der öffentlichen Sommersitzung am 27. Mai 2011)
}

\author{
ANTIONO PAU PEDRÓN
}

Sehr geehrter Herr Präsident, sehr geehrter Herr Botschafter von Spanien, sehr geehrte Damen und Herren!

Wir glauben, daß wir im Verlauf unseres Lebens wählen, und in Wirklichkeit sind wir selbst die Gewählten. Wahlheimat ist eines der schönsten Worte in dieser Sprache, die in ihrem Wörterbuch nur schöne Worte sammelt. Wer aber wählt wen? Man wählt nicht die Heimat, in der man geboren wird und die man liebt, und man wählt auch nicht jene andere ferne Heimat, die man lediglich liebt. Wir öffnen die Augen zweimal, und

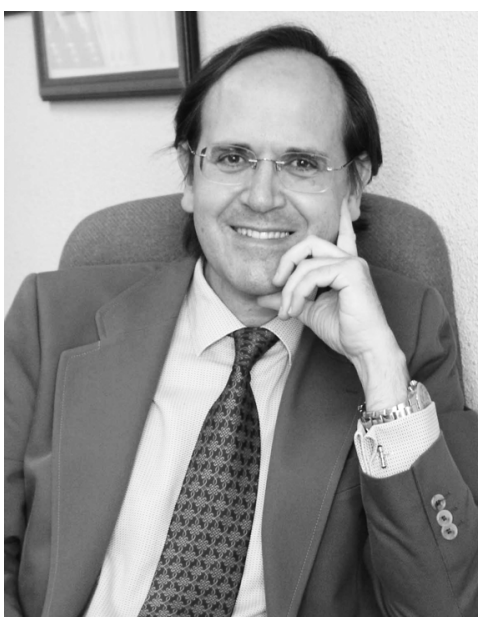

Antiono Pau Pedrón, Jurist und Schriftsteller, Madrid/Spanien, Träger der Lichtenberg-Medaille 2011 wir finden zwei Heimaten: dies sind Begegnungen mit zwei Wirklichkeiten, die wir langsam verinnerlichen.

Jene Begegnungen finden in der Kindheit statt. Und da wir nicht diejenigen sind, die wählen, bleibt uns nur übrig, im Verlaufe des Lebens sorgsam darüber zu wachen, daß die gefundenen Wirklichkeiten in unserem Inneren verbleiben.

Rainer Maria Rilke schrieb

Laß dir, daß Kindheit war, diese namenlose

Treue der Himmlischen, nicht widerrufen

vom Schicksal - denn zeitlos hält sie das Herz.

Dasselbe Schicksal, welches uns die beiden Heimaten in der Kindheit gab, kann uns dieselben wieder wegnehmen. Wir dürfen dies nicht zulassen, 
weil dadurch unsere Herzen ihren Halt verlieren und notleidend in der Leere herumirren würden.

Ich kann sagen, daß ich diesen unschätzbaren Gaben, meiner Kindheit und ihrer beiden Heimaten, treu geblieben bin. Egoistisch betrachtet: da ich ohne diese obdachlos gewesen wäre. Spanien und Deutschland haben mir die Wärme ihrer Kulturen und die Gesellschaft sowohl ihrer lebenden als auch ihrer verstorbenen Menschen gegeben; in der Entfernung dabei mehr noch die der Verstorbenen als die der Lebenden. Und sie haben mir zwei Sprachen dargebracht: zwei Welten mit eigenen Nachklängen, eigenen Klimaten und Farben, mit unterschiedlichen geistigen Landschaften.

Was Sie heute mit außerordentlicher Großzügigkeit auszeichnen, ist meine Treue zu meiner Wahlheimat. Es gibt in beiden Sprachen ein fast identisches Sprichwort, das wie alle Sprichwörter pessimistisch ist: der Prophet gilt nichts im eigenen Land. Dieses Sprichwort verliert heute glücklicherweise seine Gültigkeit für mich. Und ich wiederhole, daß ich dies nur Ihrer Großzügigkeit verdanke.

Ich erhalte diese Auszeichnung von einer der von mir am meisten bewunderten Institutionen, nämlich den Akademien. Die Akademien verbinden die Tradition ihrer Vorzeit mit der Gelassenheit ihrer Gegenwart. Die Akademien sind ruhige Festungen des Nachdenkens in einer heutigen Welt, in der Übereilung und Unbedachtsamkeit vorherrschen. Seit jenem fernen Tag ihrer Gründung im Jahre 1751 hat die Akademie der Wissenschaften zu Göttingen Gelehrte aller Fachbereiche zusammengeführt, um gemeinsam nachzudenken. Und dies erfolgte genau in einer Stadt, in der eine der berühmtesten Universitäten Deutschlands und fünf Max-PlanckInstitute angesiedelt sind, in denen so viele Schriftsteller, Künstler und Wissenschaftler auf außerordentliche Art und Weise die Kultur bereichert haben.

In einigen Monaten werden wir den hundertsten Jahrestag eines einzigartigen Zusammenflusses von deutscher und spanischer Kultur erreichen. Es handelt sich dem Anschein nach um ein minderes Ereignis, welches jedoch, mit einer Lawine vergleichbar, Auswirkungen ungeheuren Umfangs ausgelöst hat: die Reise des Dichters Rainer Maria Rilke nach Spanien. Ich möchte diesen zeitlichen Zufall nutzen, um an diese Reise zu erinnern und uns vorzustellen, wie die Beziehung Rilkes zu Spanien hätte sein können, falls gewisse Fakten anders verlaufen wären. Ich möchte ebenfalls kundgeben, daß Rilke weiterhin unter uns Spaniern ist. Ich werde nicht auf die mehrere tausend Leser ansprechen, für die Rilke zu den am meisten bewunderten europäischen Dichtern gehört, sondern möchte - innerhalb des Zeitrahmens, der mir für diesen Beitrag gegeben wurde - bei seinem 
Einfluß auf die spanischen Dichter verweilen. Daher gebe ich diesem öffentlichen Beitrag den folgenden Titel: Rilkes Beziehung zu Spanien: wie sie war, wie sie hätte sein können und wie sie ist.

\section{Wie sie war}

Rilke kam in den frühen Morgenstunden des 2. November 1912 in Madrid an und durchquerte, ohne anzuhalten, die Stadt vom Nord- zum Südbahnhof. „Fürstin, wissen Sie, daß ich eine einzige Sehnsucht habe: nach Toledo zu reisen", hatte er einige Monate zuvor an die Fürstin Maria von Thurn und Taxis geschrieben.

Nach fast zwei Stunden Zugfahrt gelangte er um zehn Uhr morgens in die Ruhe einer Stadt, die soeben aufwachte. Rilke erreichte Toledo über zwei Wege, einen Lebens- und einen ästhetischen Weg: aus Duino und aus El Greco.

In den letzen Tagen in Duino gab es eine dunkle Urkraft, die Rilke antrieb, die Reise anzutreten, an die der Dichter schon monatelang mit Freude gedacht hatte: die Reise nach Toledo. Eine junge Tote, die sich während einer Geisterglaubenssitzung als „die Unbekannte“ bezeichnet, bedient sich des Dichters, um sich auszudrücken. In einem großen Salon versammelten sich im Dunklen die Fürstin Maria, ihr Sohn Pascha, Rilke und die übrigen Schloßgäste schweigend um einen großen runden, mit roter Tischdecke versehenen Tisch herum. Rilke, der sich niemals als Medium betätigt hatte - Pascha war darin erfahrener -, nahm dieses Mal das Täfelchen und ließ, in Erwartung einer Antwort auf die Fragen, die der Dichter etwas früher auf einen Zettel geschrieben hatte, seine zitternden Hände über die Tafel voller Buchstaben und Nummern laufen. Pascha übertrug die Sätze, die dieser zitternde Lauf des Täfelchens bildete. Am Ende nahm Rilke den Zettel mit den Fragen und Pascha den mit den Antworten heraus.

Auf eine der Fragen hatte die Unbekannte geantwortet mit: „Reise den Berg hinauf, das Tal hinab nur zu den Sternen ... Wie die Wellen, tönen wirst auch du, wo Stahl sich sanft an Engel schmiegt ... "Und sie fügte als genauere Angabe zum Ziel des Dichters hinzu: „Rote Erde - Glut - Stahl Ketten - Kirchen - blutige Ketten ... Laufe voran, ich werde dir folgen ... Die Brücke, die Brücke, die Türme am Anfang und Ende ... Fühlst du die Engel? Es rauschen die Zeiten wie Wälder ... Für dich flieht wohl die Zeit, für mich steht sie still ... Wenn du hinkommst, so gehe unter die Brücke, dort, wo die großen Felsen sind, und dann singe, singe, singe."

Die Fürstin Maria von Thurn und Taxis, die den gesamten Dialog in ihren Erinnerungen wiedergab, vermerkte auch Rilkes Reaktionen: „Er war 
zum Äußersten erregt und gespannt“, „er war sehr betroffen“, „die Fragen brannten auf seinen Lippen“. Und die Fürstin selbst faßt den Dialog mit der Unbekannten wie folgt zusammen: „Toledo rief ihn“.

Fast zufällig konnte Rilke Toledo anhand der Gemälde von El Greco kennenlernen: der „Blick auf Toledo“ war nur einige Monate vorher im Pariser Herbstsalon ausgestellt worden, und der „Laokoon“ gehörte nur drei Jahre lang der Münchener Pinakothek. Man kann sich leicht vorstellen, welchen Eindruck diese Gemälde auf den Dichter machten, wenn man seine Worte aus dem Jahre 1912 beachtet:

Greco gehört zu den größten Ereignissen meiner letzten zwei oder drei Jahre; das Bedürfnis, sich gewissenhafter mit ihm einzulassen, sieht beinah wie eine Berufung aus, wie eine tief innen eingesetzte Pflicht.

Rilke versetzt sich in die Gemälde, um diese zu verinnern, um diese zur Substanz seiner eigenen Poesie zu machen. Der Dichter, der mit dem einzigen Drang lebte, sein Werk abzuschließen, bereitete in den grauen und bitteren Zeiten, in denen er dies nicht tat, sorgfältig seine Intimität vor, aus der dieses Werk sprießen sollte.

Aus diesem Grund sagt er der Fürstin Maria in einem Brief vom 27. September 1911, daß er die El Grecos in München „sah und wiedersah, durchmachte, erlebte“. Die vor dem „Blick“verbrachten unbeweglichen Stunden und die vor dem „Laokoon“ verlebten Tage erlauben ihm, sich in zwei an Rodin und die Fürstin gesandten Briefen an alle Einzelheiten zu erinnern und dieselbe Ergriffenheit neu aufleben zu lassen:

Mein lieber Rodin: Ich komme vom Salon, in dem ich eine Stunde vor El Grecos Toledo verbracht habe. Diese Landschaft erscheint mir jedes Mal überraschender. Ich muß es so beschreiben, wie ich es gesehen habe. Und zwar:

Das Gewitter ist entfesselt und entlädt sich plötzlich hinter einer Stadt, die an einem Berghang liegt, steigt schnell zur Kathedrale auf und noch höher zur viereckigen, massiven Burg. Lichterfetzen durchfurchen die Erde, umgraben, zerreißen sie und lassen hellgrüne Wiesen erscheinen, und hinter Bäumen wie schlaflose Geschöpfe. Ohne Bewegung entspringt ein schmaler Fluß aus dem Hügelhaufen und bedroht erschreckend blauschwarz und nächtlich die grünen Flammen des Gebüschs. Die erschrockene, bestürzte Stadt klettert mit einer letzten Anstrengung bei dem Versuch, die von der Atmosphäre geschaffene Angst zu überwinden.

Rilkes Beschreibung des „Laokoons“ im Brief vom 27. September 1911 an die Fürstin Maria von Thurn und Taxis ist nicht weniger ausdrucksvoll und genau:

... ich schrieb ihnen davon, kam aber wohl nicht dazu, zu erzählen, daß da dieser seltsame Laokoon war: stellen Sie sich vor, ein geräumiges Bild, im Vordergrund auf braunem steinigem, von den Wolken herüber rasch und tragisch verdunkeltem Erd- 
reich, Laokoon, umgerissen von der Schlange, die er hinter sich wegzuhalten versucht, einer der Söhne schon gefällt, einer links, stehend, zurückgekrümmt und wieder gespannt von dem starken Bogen der zweiten Schlange, die ihm schon ans Herz reicht, zwei Söhne rechts noch kaum begreifend (so schnell wälzte sich das heran und nahm überhand), und durch alles das hindurch, durch Sehen und Stürzen und Widerstand, durch alle die spannenden Zwischenräume dieser Verzweiflung durch - Toledo gesehen, wie wissend von diesem Schauspiel, hinaufgedrängt auf seine unruhigen Hügel, bleich von dem Schein der hinter ihm hinstürzenden Himmel -. Ein unvergeßliches Bild ... Es müßte herrlich sein, diese Stadt zu sehen und den Greco im Zusammenhang mit ihr.

Am selben Tage, an dem Rilke in Toledo ankam, durchstreifte er die ganze Stadt, überquerte die Brücken und betrachtete jene vom anderen Ufer aus. Um sieben Uhr abends kehrte er müde und begeistert ins Hotel zurück, wo er einen der schönsten Briefe seines unermeßlichen Schriftverkehrs schrieb. Die Adressatin konnte keine andere als die Fürstin Maria sein:

Fürstin, Ihnen das erste Wort, sei es: Hoffnung, und wenn schon gleich wieder ein Wunsch mitsprechen darf: es möchte lange kein anderes mir klarwerden, damit ich mich in diesem hier arglos und unbegrenzt einrichten kann.

Sagen können, wie es hier ist, werd ich ja nie, liebe Freundin (da ist Sprache der Engel, wie sie sich unter den Menschen helfen), aber daßes ist, daß es ist, das müssen Sie mir aufs Geratewohl glauben. Man kann es niemandem beschreiben, es ist voll Gesetz, ja, ich begreife augenblicklich die Legende, daß Gott, da er am vierten Schöpfungstag die Sonne nahm und stellte, sie genau über Toledo errichtete: so sehr sternisch ist die Art dieses ungemeinen Anwesens gemeint, so hinaus in den Raum -, ich bin schon überall herumgekommen, hab mir alles eingeprägt, als sollt ichs morgen für immer wissen, die Brücken, beide Brücken, diesen Fluß und, über ihn hinüber verlegt, diese offene Menge der Landschaft, übersehbar wie etwas, woran noch gearbeitet wird. Und dieses Glück der ersten Wege, die man versucht, dieses unbeschreiblich sichere Genommen- und Geführtsein -, stellen Sie sich vor, ich nahm die Gasse Santo Tomé, dann die des Engels, und sie brachte mich vor die Kirche San Juan de los Reyes, an deren Mauern lauter Ketten Gefangener oder Befreiter in Reihen herabhängen und auf den Gesimsen aufruhen .... Und dann weiter, nirgends wars zufällig, und fast hat man Lust, sich umzusehen, bei solchem Entdecken, wie um zu erfahren, wer eigentlich zuschaut, wem man damit eine Freude macht, wie Kinder sich umsehen, wenn sie etwas lernen.

Während seiner zurückgezogenen Tage in Toledo schrieb Rilke ein fragmentarisches Gedicht. Es ist ein unartikuliertes, elliptisches Bruchstück eines Gedichts, in dem das Du mit den Konstellationen, den Blumen, der Nacht, dem Wind und den Vögeln verbunden ist. Die Verbindung dieses Gedichts mit der Stadt Toledo findet man in den letzten Strophen, in den wunderschönen Versen, in denen der Dichter denkt an 
... wieviel Zärtlichkeit

getaucht ins Blut,

ins lautlose Herzblut

so geliebter Dinge

womit er fast wörtlich den Ausruf wiederholt, den einer seiner Briefe in Bezug auf die Stadt enthält, die er gerade betrachtet:

Mein Gott, wie viele Dinge hab ich lieb gehabt, weil sie etwas von diesem da zu sein versuchten, weil ein Tropfen dieses Blutes in ihrem Herzen war!

Dieses Bruchstück ist eines der wenigen, denen Rilke einen Titel gab, „An die Erwartete":

... komm wann du sollst. Dies alles wird durch mich hindurchgegangen sein zu deinem Atem.

Ich habs, um deinetwillen, namenlos

lang angesehen mit dem Blick der Armut

und so geliebt als tränkst du es schon ein.

Und doch: bedenk ichs, daß ich dieses, mich,

Gestirne, Blumen und den schönen Wurf.

der Vögel aus nachwinkendem Gesträuch,

der Wolken Hochmut und was nachts der Wind

mir antun konnte, mich aus einem Wesen

hinüberwandelnd in ein nächstes, $-\mathrm{da} ß$

ich eines nach dem andern, denn ich bins,

bin was der Tränke Rauschen mir im Ohr

zurückließ, bin der Wohlgeschmack, den einst

die schöne Frucht an meinen Lippen ausgab, -

$\mathrm{da}$ ich dies alles, wenn du einmal da bist,

bis rückwärts zu des Kindes niederm Anblick

in Blumenkelche, da die Wiesen hochstehn,

ja bis zu einem Lächeln meiner Mutter

das ich vielleicht, gedrängt von deinem Dasein,

annnehme wie Entwendetes -, daß ich

dann unerschöpflich Tag und Nacht soviel

entbehrend angeeignete Natur

hingeben sollte -, wissend nicht, ob das

was in dir aufglüht Meines ist: vielleicht

wirst du nur schöner, ganz aus eigner Schönheit

vom Überfluß der Ruh in deinen Gliedern,

vom Süßesten in deinem Blut, was weiß ich,

weil du dich selbst in deiner Hand erkennst,

weil dir das Haar an deinen Schultern schmeichelt,

weil irgendetwas in der dunkeln Luft

sich dir verständigt, weil du mich vergißt, 
weil du nicht hinhörst, weil du eine Frau bist:

wenn ichs bedenke, wie ich Zärtlichkeit

getaucht ins Blut, ins nie von mir erschreckte

lautlose Herzblut so geliebter Dinge

Gefangen von der Anmut der zwischen den Steinen aufstrebenden Feigenbäume, deren weißer Saft und saftige Früchte im Überfluß vorhanden sind, ohne ihre Wurzeln in die Erde einzutreiben, beginnt er in Toledo mit dem Schreiben der „Sechsten Elegie“. Rilke beneidet die wunderbare Fruchtbarkeit und auch die elegante Diskretion des blütenlosen Baums.

Feigenbaum, seit wie lange schon ists mir bedeutend, wie du die Blüte beinah ganz überschlägst und hinein in die zeitig entschlossene Frucht, ungerühmt, drängst dein reines Geheimnis.

Wie der Fontäne Rohr treibt dein gebognes Gezweig abwärts den Saft und hinan: und er springt aus dem Schlaf, fast nicht erwachend, ins Glück seiner süßesten Leistung.

Ich möchte besonders auf zwei Erlebnisse Bezug nehmen, die der Dichter in Toledo hatte und die mit einem zentralen Aspekt in Rilkes Person und Werk in Beziehung stehen, und zwar: die verschiedenen Gegenüberstellungen „sichtbare und unsichtbare Welt", „Außenwelt und Innenwelt“, oder, wie er in zwei anderen Äußerungen in dem berühmten Brief an seinen polnischen Übersetzer Witold Hulewicz sagt, die „beiden Seiten des Lebens“, die „beiden unabgegrenzten Bereiche“, das „Diesseits und Jenseits“, die „die große Einheit“ bilden, ,in der die Engel zu Hause sind“.

Das erste Erlebnis in Toledo: die Engel. Die Engel sind die Wesen, die ohne Schwierigkeiten von der sichtbaren in die unsichtbare Welt schreiten.

Rilke findet in Toledo die natürliche Heimat der Engel. Weil Toledo, wie der Dichter sagt, „eine Stadt des Himmels und der Erde“ ist, „eine Stadt, die in gleichem Maße für die Augen der Verstorbenen, der Lebenden und der Engel sei“.

Rilke schreibt deshalb, daß es in Toledo ist, wo er „die Realität der Engel“ begreifen lernen kann:

Nichts wie Toledo, wenn man sich seinem Einfluß überließe, vermöchte in solchem Grade zur Darstellung des Übersinnlichen ausbilden, indem die Dinge dort die Intensität dessen haben, was gemeinhin und täglich nicht sichtbar ist: die Erscheinung.

Rilkes Engel ist kein jungfräulicher Engel der religiösen Malerei, sondern ein vogelhafter Engel, der ohne Rast die Welt der Lebenden und die der Toten durchquert. Und der Dichter findet diese Engel mit langen und genauen Vogelflügeln in den Gemälden des El Greco. Vogelhafte Engel, die 
perspektivisch verkürzt aufsteigen und die Erd- und die Himmelsszenen verbinden, die aus den Profilen Toledos angetrieben werden und die Arme erheben, bis sie mit den Heiligen vereint sind. Rilke schreibt, daß „das Wesen dieser Engel des Greco fließend ist, er ist der Fluß, der durch beide Reiche geht, ja, was das Wasser auf Erden und in der Atmosphäre ist, das ist der Engel in dem großen Umkreis des Geistes, Bach, Thau, Tränke, Fontäne des seelisches Daseins, Niederschlag und Aufstieg“"

Rilke schreibt, daß die Engel den Übergang „vom Sinnlichen ins Übersinnliche" mit Natürlichkeit durchführen. Aus diesem Grunde betrachtet Rilke immer wieder das Gemälde der „Himmelfahrt“ in der kleinen, in ein Museum umgewandelten Mudejarkirche von San Vicente, in dem sich ein schwereloser Engel über die gesamte himmelsblaue Tunika von den Füßen bis zu den Händen der Jungfrau erstreckt:

Ein großer Engel drängt schräg ins Bild hinein, zwei Engel strecken sich in die Höhe, und aus dem Überschuß von alledem entsteht purer Aufstieg und kann gar nichts anders. Das ist Physik des Himmels.

Rilke wollte, daß diese Gemäldeszene sein letztes Andenken an die Stadt sei, wie er Leo von Künig im Brief vom 20. Dezember sagt. Als er später das Gedicht der „Himmelfahrt Mariae“ schreibt, erinnert er sich immer noch daran, wie Maria sich beim Aufstieg ,aus den Blumenkelchen,/ aus dem Vogel, der den Flug beschreibt, nimmt":

I

Köstliche, o Öl, das oben will,

blauer Rauchrand aus dem Räucherkorbe,

grad-hinan vertönende Theorbe,

Milch des Irdischen, entquill,

still die Himmel, die noch klein sind, nähre

das dir anruht, das verweinte Reich:

Goldgewordne wie die hohen Ähre,

Reingewordne wie das Bild im Teich.

Wie wir nächtens, daß die Brunnen gehen, hören im vereinsamten Gehör:

bist du, Steigende, in unserm Sehen

ganz allein. Wie in ein Nadelöhr

will mein langer Blick in dir sich fassen,

eh du diesem Sichtlichen entfliehst, -

$\mathrm{da}$ du ihn, wenn auch ganz weiß gelassen,

durch die farbenechten Himmel ziehst. 
II

Nicht nur aus dem Schaun der Jünger, welchen

deines Kleides leichte Wehmut bleibt:

ach, du nimmst dich aus den Blumenkelchen,

aus dem Vogel, der den Flug beschreibt;

aus dem vollen Offensein der Kinder,

aus dem Euter und dem Kaun der Kuh -;

alles wird um deine Milde minder,

nur die Himmel innen nehmen zu.

Hingerissne Frucht aus unserm Grunde,

Beere, die du voller Süße stehst,

laß uns fühlen, wie du in dem Munde

der entzückten Seligkeit zergehst.

Denn wir bleiben, wo du fortkamst. Jede

Stelle unten will getröstet sein.

Neig uns Gnade, stärk uns wie mit Wein.

Denn vom Einsehn ist da nicht die Rede.

Und im Pradomuseum macht El Grecos „Kreuzigung“, in der zwei Engel das Kreuz von der Erde in den Himmel zu schieben scheinen, den größten Eindruck auf ihn.

Mit den Engeln des Greco in der Erinnerung schrieb Rilke zwei den Engeln gewidmete Gedichte. In einem, unmittelbar nach seiner Betrachtung in Toledo, sagte er, daß der Engel sei wie ein

Starker, stiller, an den Rand gestellter

Leuchter: oben wird die Nacht genau.

Wir vergeben uns in unerhellter

Zögerung an deinem Unterbau.

Unser ist: den Ausgang nicht zu wissen aus dem drinnen irrlichen Bezirk, du erscheinst auf unsern Hindernissen und beglühst sie wie ein Hochgebirg.

Viele Jahre später, in einem anderen Gedicht, durchqueren die Engel die Szene immer noch mit festem Kurs, während die Menschen ungeschickt versuchen, ihren Weg zu finden:

Siehe, Engel fühlen durch den Raum.

Während uns, die wirs nicht anders wissen,

eins sich wehrt und eins umsonst geschieht,

schreiten sie, von Zielen hingerissen,

durch ihr ausgebildetes Gebiet. 
Die Engel sind die vorherrschenden Wesen in den „Duineser Elegien“: vom Beginn der „Ersten“ - „Wer, wenn ich schriee, hörte mich denn aus der Engel Ordnungen?“ - bis zum Beginn der „Zehnten“ und letzten - „Daß ich dereinst, an dem Ausgang der grimmigen Einsicht, / Jubel und Ruhm aufsinge zustimmenden Engeln". Durch die Verflechtung der Frage im ersten Satz mit dem im zweiten ausgedrückten Wunsch wird der Übergang klar: „jetzt“, in dieser „sichtbaren Welt", fühlt sich der Dichter weit von den Engeln entfernt, die seine Angstschreie nicht erreichen können; „dann“, „an dem Ausgang“, das heißt, an der Schwelle, die die sichtbare von der unsichtbaren Welt trennt, trachtet - vertraut, erwartet - der Dichter nicht nur, von ihnen gehört zu werden, sondern mit ihnen mit "Jubel und Ruhm“ zu singen.

Sie, die Engel, sind die Wesen, die mit Natürlichkeit beide Welten durchqueren, die ohne Hindernisse durch die sichtbare und die unsichtbare streifen. Wie er in der „Ersten Elegie“ sagt:

Engel (sagt man) wüßten oft nicht, ob sie unter

Lebenden gehn oder Toten. Die ewige Strömung

reißt durch beide Bereiche alle Alter

immer mit sich und übertönt sie in beiden.

Die erste Strophe der "Zweiten Elegie“ offenbart den erschütternden Aspekt, den Engel als übernatürliche Kreatur. Die zweite Strophe ist eine brillante Abfolge von Metaphern, mit denen der Dichter die Engel beschreibt.

Jeder Engel ist schrecklich. Und dennoch, weh mir, ansing ich euch, fast tödliche Vögel der Seele, wissend um euch. Wohin sind die Tage Tobiae, da der Strahlendsten einer stand an der einfachen Haustür, zur Reise ein wenig verkleidet und schon nicht mehr furchtbar;

(Jüngling dem Jüngling, wie er neugierig hinaussah).

Träte der Erzengel jetzt, der gefährliche, hinter den Sternen eines Schrittes nur nieder und herwärts: hochaufschlagend erschlüg uns das eigene Herz. Wer seid ihr?

Frühe Geglückte, ihr Verwöhnten der Schöpfung, Höhenzüge, morgenrötliche Grate aller Erschaffung, - Pollen der blühenden Gottheit, Gelenke des Lichtes, Gänge, Treppen, Throne, Räume aus Wesen, Schilde aus Wonne, Tumulte stürmisch entzückten Gefühls und plötzlich, einzeln, Spiegel: die die entströmte eigene Schönheit wiederschöpfen zurück in das eigene Antlitz. 
Zweites Erlebnis in Toledo: der Absturz des Sterns. Eines Abends kehrt der Dichter von den Bergen, die Toledo umgeben, in die Stadt zurück. Er hat stundenlang betrachtet, wie die Sonne und die Wolken das Vorgebirge erleuchteten und erblassen ließen, auf dem die Stadt angesiedelt ist. Obwohl es nicht spät ist, ist die Nacht bereits eingefallen, und die Kälte ist plötzlich in die Tajoschlucht eingedrungen. Seine Schritte hallen wider, als er sich der San Martín-Brücke nähert. Der äußere Turm ist einer der Lieblingsorte des Dichters. Nachdem er in diesem verweilt hat, beginnt er, über die Brücke zu gehen. Nach wenigen Schritten verweilt er erneut. Es gibt keine einzige Wolke, und der Himmel hat sich, wie in einer klaren Sommernacht, mit Lichtern gefüllt. Plötzlich erhebt sich ein großer Stern, steigt wie eine Lichtfontäne und fällt und fällt noch mehr, langsam, immer größer und röter, durchfliegt majestätisch den unendlichen Raum, der sich zwischen den beiden Ufern erhebt, und stürzt in der Stille hinter die im Halbdunkel liegende Stadt.

Sieben Jahre später fühlt der Dichter dieses Erlebnis erneut mit derselben Intensität wie in jener Novembernacht:

Ich stand nachts auf der wunderbaren Brücke von Toledo, da mir in gespanntem langsamen Bogen durch den Weltenraum fallender Stern zugleich (wie sollte ich das sagen?) durch den Innenraum fiel: die trennende Kontur des Körpers war nicht mehr da.

In den letzten Versen eines im Jahre 1915 in München geschriebenen, überraschenden Gedichtes, „Der Tod“, erscheint die Erinnerung an die Brücke und den Stern, die nicht zu erklären wäre, wenn die Episode in Toledo nicht bekannt wäre:

O Sternenfall,

von einer Brücke einmal eingesehn:

dich nicht vergessen. Stehn!

Die Spur des Sterns kann in anderen Gedichten Rilkes gefunden werden: es ist wahrscheinlich derselbe Meteor, der "Die spanische Trilogie“ durchquert; der „Sternenfall“ ist eines der Gedichte der späteren Jahre - „Nachthimmel und Sternenfall“ -, geschrieben im Sommer 1924; und auch die Vögel, die die Intimität des Dichters in einem der letzten Gedichte durchbohren:

Die Vögel fliegen still durch uns hindurch.

Dieses Brückenerlebnis ist jedoch nicht das erste, bei dem Rilke die Auflösung der Kontur des Körpers fühlt und mit der er die doppelte Perzeption der „beiden Seiten der Wirklichkeit“ fühlt. Mit entblößter Empfindlichkeit in unmittelbarem Kontakt mit der Natur war er kurz bei zwei weiteren 
Gelegenheiten gewesen: in Duino und in Capri. Der Dichter erzählt diese Episoden in einem Prosatext mit dem Titel „Erlebnisse“, den er in Ronda zu schreiben begann und 1919 in München abschloß.

Beim Spaziergang durch den Garten des Schloßes Tybein lehnte er sich an einen dem Meer gegenüberliegenden Busch. Er fühlte dabei unmittelbar eine vollkommene gegenseitige Durchdringung mit der Natur. Er erzählte das Erlebnis in der dritten Person:

Nach und nach erwachte eine Aufmerksamkeit über einem niegekannten Gefühl: es war, als ob aus dem Innern des Baumes fast unmerkliche Schwingungen in ihn übergingen ....Er meinte nie von leiseren Bewegungen erfüllt worden zu sein, sein Körper wurde gewissermaßen wie eine Seele behandelt und in den Stand gesetzt, einen Grad von Einfluß aufzunehmen, der bei der sonstigen Deutlichkeit leiblicher Verhältnisse eigentlich gar nicht hätte empfunden werden können.

Im Garten in Capri fühlte er, wie der Gesang eines Vogels gleichzeitig in der Luft und in seinem Innern bebte.

Ein Vogelruf draußen und in seinem Innern übereinstimmend da war, indem er gewissermaßen an der Grenze des Körpers nicht brach, beides zu einem ununterbrochenen Raum zusammennahm... Damals schloß er die Augen, um in einer so großmütigen Erfahrung durch den Kontur seines Leibes nicht beirrt zu sein, und es ging das Unendliche von allen Seiten so vertraulich in ihn über, daß er glauben durfte, das leichte Aufruhn der inzwischen eingetretenen Sterne in seiner Brust zu fühlen.

Dieser „Orkan im Geist“ im Januar 1922, welcher ihm in zwanzig Tagen die letzten Gedichte der „Elegien“ und die fünfundfünfzig „Sonette an Orpheus" entriß, hatte nichts mit den vorhergehenden Erlebnissen oder dem Gefühl zu tun, ohne Körper in die Natur einzudringen. Nichts lag der Gelassenheit dieses gegenseitigen Durchdringens ferner als die Spannung von Fasern und Stoffen, die kurz vor dem Zerreißen sind, die er während der fieberhaften Arbeitstage in Muzot fühlte.

Rilke verläßt Toledo, weil sein kranker Körper den Winter nicht aushält. Aber er verläßt die Stadt „,beständig zurückschauend“.

Ich sah es zuende gehn, konnte nichts dagegen tun; ähnlich wie wenn ich als Kind Musik hörte und wünschte, es möchte immer weiter dauern: auf einmal fingen die Geigen an, zu unterstreichen und das war nur noch wie ein Ausholen zu dem einen starken Strich unter das Ganze, hinter dems zu Ende war. So war auch dort, alles, was man noch tat und versuchte, ein Unterstreichen, ich begriffs und ging herum und lockerte mich.

In den ersten Briefen, die er aus dem Süden schickt, ist ihm nur die Stadt vor Augen, die er zurückgelassen hat. Vielleicht sind die schönsten Beschreibungen diejenigen, die er aus der Erinnerung und aus Nostalgie 
machte; in diesen sagt er auch, daß Toledo für ihn „ein ständiger Gegenstand der Bewunderung gewesen ist, dem er Tag und Nacht beipflichtete“.

Als er im Jahr 1914 nach München zieht und Frieden in einer kleinen Wohnung gegenüber dem Englischen Garten findet, fordert er von allen Einsamkeit und Abstand und beginnt zu schreiben, indem er „die Außenwelt vermeidet, um die Worte zu finden, mit denen er die Erfahrungen von Moskau bis Toledo ausdrücken kann“. Aus diesen Monaten stammt das Gedicht „Der Tod“, das mit der Episode des Sterns endet, der hinter der San Martin-Brücke fällt, und die „Vierte Elegie“.

Und auch als der Dichter am Rande der Erschöpfung und Verzweiflung, die die Grauen des Krieges in ihm hervorriefen, glaubte, daß er die „Elegien“ nicht werde vollenden können, erscheint Toledo. „Wozu hat man Toledo gekannt, wozu die Wolga, wozu die Wüste, um jetzt in dem engsten Welt-Widerruf dazustehen, voll plötzlich unanwendbaren Erinnerungen?" - schreibt er an den Verleger Kurt Wolff am 28. März 1917.

Als er einige Jahre später - im Jahre 1921 -, erneut glaubt, daß er die „Elegien“ vollenden könne, nachdem die Grauen des Krieges überwunden sind, erwähnt er wiederum Toledo. In einem Brief vom 3. Juni an Paul Adler sagt er diesem, daß er bereits die Hoffnung hege, daß die Erinnerungen an „jene vertrauten und erhabenen Städte: Moskau, Toledo, Paris“ in ihm aufflammen können.

Rilke begab sich auf die Reise nach Süden in der Annahme, daß er dort sanftere Gegenden finden werde. Aber Cordoba reizt und Sevilla enttäuscht ihn.

Cordoba. Diese Moschee; aber es ist ein Kummer, ein Gram, eine Beschämung, was man daraus gemacht hat, diese in das strähnige Innere hineinverfitzten Kirchen, man möchte sie auskämmen wie Knoten aus schönem Haar. Wie große Brocken sind die Kapellen der Dunkelheit im Hals stecken geblieben, die darauf angelegt war, Gott fortwährend mild zu verschlucken wie Saft einer Frucht die zergeht. Noch jetzt wars rein unerträglich, die Orgel und das Respondieren der Chorherren in diesem Raum zu hören, das Christentum, dachte man unwillkürlich, schneidet Gott beständig an wie eine schöne Torte, Allah aber ist ganz, Allah ist heil.

Während er in Toledo „einen unbeschreiblichen Wunsch, Gott zu fühlen“, erlebt hat, so fühlt er auf seiner Wegstrecke nach Süden eine ungeheure spirituelle Trostlosigkeit. „Hier ist eine Gleichgültigkeit ohne Grenzen, leere Kirchen, vergessene Kirchen, Kapellen, die verhungern“. Und während er in Toledo behauptete, daß es angesichts der Landschaft der kastilischen Stadt nur billig sei, die Bibel zu öffnen und zu lesen, flammt in Cordoba ein unwiderstehlicher Drang auf, den Koran zu lesen. In der andalusischen Stadt befällt ihn seine berühmte „beinah rabiate Antichristlichkeit“. 
Ich bin von einer beinah rabiaten Antichristlichkeit, ich lese den Koran, er nimmt mir, stellenweise, eine Stimme an, in der ich so mit aller Kraft drinnen bin, wie der Wind in der Orgel [...] Mohammed bricht durch zu dem einen Gott, mit dem sich so großartig reden läßt jeden Morgen, ohne das Telephon ,Christus', in das fortwährend hineingerufen wird: Holla, wer dort? - und niemand antwortet.

Von Sevilla ist Rilke enttäuscht, aber nicht überrascht. „Von Sevilla, offengestanden, hab ich nichts erwartet, und es gibt mir auch weiter nichts; wir haben einander nichts vorzuwerfen“. „Mir war die Kathedrale so von Grund aus zuwider, ja, feindlich“. Er findet sie angeberisch: „Sie will auch Gott noch übertrumpfen und ihn, gewissermaßen, von oben fassen“. Orgeln, in denen er in Toledo eine unbeschreibliche Erhabenheit fand, betrachtet er hier, in Sevilla, als „verabscheuungswürdig“. „Die Orgeln machen den Raum so süß, daß die kolossalen Pfeiler ganz schwach werden“".

Rilke erreicht am 9. Dezember 1912 Ronda und zieht in ein kleines Zimmer im Reina Victoria Hotel ein, das seitdem für den Dichter reserviert geblieben und in ein kleines Museum umgewandelt worden ist, welches seinem Andenken gewidmet ist. Rilkes Zimmer schaut auf diese weite Landschaft hinab, die der Stadt zu Füßen liegt. Das von Engländern geführte Hotel hatte eine kosmopolitische Atmosphäre, die ganz anders als das provinzielle Ambiente des Hotels Castilla war, in dem Rilke während seines Aufenthaltes in Toledo gewohnt hatte. Der großzügige Garten des Reina Victoria Hotels verläuft wie ein Kiel vom Stadtrand, und ein niedriges Geländer trennt diese angenehme Einfriedung mit Lauben und Brunnen vom Abgrund. Unten erstreckt sich majestätisch das breite Flußtal des Gudalevín, das sich in einer windenden Ebene bis ins Gebirgsland ausdehnt.

Die ersten von Rilke aus Ronda gesandten Briefe zeigen sein Entzücken über die Stadt. „Hier in Ronda - schreibt er am 11. an Sidony Nadherny ist starke herrliche Luft, Berge wie aufgeschlagen, um Psalmen daraus vorzusingen, - und auf eine Bergplatte gehäuft eine der ältesten und seltsamsten spanischen Städte."

An die Fürstin Maria von Thurn und Taxis schreibt er eine Woche später, am 17. Dezember:

Diese unvergleichliche Erscheinung dieser auf zwei steilen Felsmassen, die die enge tiefe Flußschlucht trennt, hinaufgehäuften Stadt seinem Traumbild recht gäbe; es ist unbeschreiblich, um das Ganze herum ein geräumiges Tal, beschäftigt mit seinen Feldflächen, Steineichen und Ölbäumen, und drüben entsteigt ihm wieder, wie ausgeruht, das reine Gebirg, Berg hinter Berg, und bildet die vornehmste Ferne. Was die Stadt selbst angeht, so kann sie in diesen Verhältnissen als eigen sein, steigend und fallend, da und dort so offen in den Abgrund, daß gar kein Fenster hinzuschauen wagt, kleine Paläste hinter Krusten von jährlicher Weiße, jeder mit farbig abgesetztem Por- 
tal, und unterm Balkon das Wappen mit etwas gedrückter Helmzier, aber im Schild deutlich, ausführlich und voll wie ein Granatapfel.

Wenige Tage, nachdem er in Ronda angekommen ist, beginnt Rilke jedoch immer stärker einen schmerzhaften inneren Bruch zu fühlen: einerseits nimmt er die unübertreffliche Großartigkeit der Orte wahr, die er erreicht hat - „meine Reise begann an einem Höhepunkt und ist unaufhaltsam gestiegen, bis sie auf dieser Warte verweilt; was nun noch kommt, kann nur ein Abstieg sein"-, wobei er andererseits seine Unfähigkeit fühlt, dies geistig zu verarbeiten. Worin hätte für den Dichter diese geistige Verarbeitung bestanden? Indem er dort selbst, in Worte verwandelt, in jenem Augenblick in der Lage gewesen wäre, diese großartige Landschaft in eine großartige Hymne zu übertragen. Dies geschieht nicht, und deshalb erreicht seine Angst nicht gekannte Grenzen. „Es gab wieder eine Reihe recht verdrießlicher Tage, Schmerzen körperlich und die Seele so wenig zum Aushalten gestimmt“, „mir stürzt die Welt jeden Augenblick völlig ein, im Blut“, „kaum daß ich irgendwo ein kleines Beet habe, schon steigt diese Trübnis und überschwemmts und läßts trostlos zurück“".

Der Dichter war in Ronda am Rande des Selbstmordes. Aber vielleicht ließ ihn seine Angst mit übertriebenem Realismus das Schwindelgefühl eines Falls von der Alten Brücke vorstellen, und er sah davon ab.

Und plötzlich verändert sich sein Gemüt vollständig. In der Woche vom sechsten bis zum vierzehnten Januar 1913 verläßt der Dichter kaum sein Hotelzimmer. Vers um Vers entsteht ein langes Gedicht, das durch Bilder, lang zurückliegende Erlebnisse und unmittelbare Szenen, die er vom Fenster aus sieht, ausgelöst wird. Es ist die monumentale „Spanische Trilogie“, das umfangreichste Gedicht, das Rilke in Spanien geschrieben hat.

Die Erklärung dieses langen Gedichts ist in einem Brief enthalten, den Rilke an die Frau seines Herausgebers, Katharina Kippenberg, am 27. März 1913 schrieb. Im ersten Teil erläutert er seine Gemütsverfassung, in die ihn die spanische Landschaft versetzte; im zweiten, dem Text der „Trilogie“ näherstehenden Teil kehrt er zum Symbol der menschlichen Existenz zurück, die er in der Person des Hirten verkörpert sieht.

Ganz im Gegenteil zu Paris, war man in Spanien durchaus in der Fremde, nie an ein Dasein gelehnt, beständig der Vision gegenüber, vor hingerissenen Dingen als Zurückbleibender dastehend, nicht wie hier überall von hinreißenden mitgenommen. Ich werde wohl erst mündlich einmal erzählen können, im Augenblick hat Paris unbeschreiblich die Oberhand über alles Vergangene, wie stark und heftig es auch war, oder eben weil es so stark und heftig war, daß sich Paris, das licht und mild von allen Seiten einen Durchdringende, dazu verhält, wie die Rekonvaleszenz zum Fieber. Ich war, je länger ich blieb, desto mehr innerlich unterbrochen in Spanien, das Extati- 
sche der Landschaft beschämt jeden Moment, nur der unaufhörlich erhobene Heilige oder der ohne Aussicht aufgelehnte Held sind auf der Höhe dieser Umgebungen, die anderen stehn finster in ihren Mänteln davor und machen sich, was sie umgibt, als Hintergrund.

\section{Und etwas später fügt er hinzu:}

Der Ausgang, morgens, der Hirten da hinaus, wenn sie, ausgeruht, den langen Stab waagrecht hinter den Schultern tragen, - ihr stilles, verweilendes, nachdenkliches Draußensein, durch welches hin in seiner ganzen Breite die Größe des Tages strömt, und die Abende wenn sie, unkenntlich, mit der Dämmerung, aus den Tälern heraufsteigen in der ihren Herden nachklingenden Luft und sich oben auf dem Rand noch einmal, schwarz, zur einfachsten Gestalt zusammennehmen; und daß sie die lange Schleuder aus Bast noch gebrauchen, in die David die Stein legte, und mit gezieltem Wurf ein abseitiges Tier zurückzuschrecken in die Masse der Herde; und daß die Luft Farbe und Geweb ihrer festen Kleider kennt und damit umgeht wie mit dem anderen Bestand der abgehärteten Natur; kurz, daß da Menschen sind, hinaus in die Fülle von Einfluß gestellt, die wir nur manchmal, heraustretend aus Beziehungen oder aufschauend aus einem Buch, gewahren: wie sie ist und anhält und fast göttlich vor sich geht, ungedrängt, über den sich drängenden Vorgängen, mit denen wir uns hinbringen: dies konnte wohl zu den reinen Erfahrungen zählen, von denen man die Tage und Nächte, im Ganzen bedeutend, ohne Nebensinn, sich von Zeit zu Zeit wieder mag beibringen lassen. Das Menschliche, das man hier mit soviel Einsicht und Genuß in den Gesichtern aufgeschlagen sieht, ist in Spanien versteckt, vergraben zusammengeballt, es muß einem schon herausgerissen werden, oder man wird selber zum Vulkan und schleudert es aus. Der Bettler ist eine Hand, in Spanien, die sich aus einem überall verdeckten Schicksal heraushält, hier ist er so bloß wie ein Strauch, an dem das Elend in Blüte kommt vor den Blättern. Und es ist neu und beschäftigt mich grenzenlos, nach jener elementaren, diese bildliche Welt wieder vorzufinden, die sich zeigt, die sich aussagt, die überall Gesichter bildet -, Gesichter der Erwartung, der Neugier, der Abkehr, Gesichter, zu denen alles kommt, und Gesichter, von denen alles unaufhörlich fortgeht, schauende Gesichter, durch die die Vögel fliegen, und angeschaute Gesichter, die nur stillhalten.

Eigentlich besteht die Spanische Trilogie aus drei Gedichten, denen drei römische Ziffer vorangehen.

Das erste Gedicht der Trilogie ist ein Gebet, in dem der Dichter eindringlich darum bittet, daß sich das Gedicht - „das Ding“ -, das er so eifrig verfolgt, verwirkliche:

aus mir und alledem ein einzig Ding

zu machen, Herr [...]

aus nichts als mir und dem, was ich nicht kenn,

das Ding zu machen, Herr Herr Herr, das Ding,

das welthaft-irdisch wie ein Meteor

in seiner Schwere nur die Summe Flugs

zusammennimmt $[\ldots]$ 
Das zweite Gedicht schickt einen Begriff voraus, der ein Jahr später einen Namen bekommen wird: der "Weltinnenraum“, die Summe aller sichtbaren und unsichtbaren Dinge, die im Inneren des Menschen Gestalt annimmt.

Im dritten Gedicht stellt Rilke die künstliche Landschaft der Stadt - mit ihrem „verwickelten Lärmknäul“ - und die natürliche Landschaft, die sich vor seinen Augen erstreckt - „der Himmel und der erdige Bergrand, / den von drüben heimwärts die Herde betrat" -, entgegen. Und er verspricht sich selbst, dem Vorbild des Hirten treu zu bleiben, der trotz der ständigen Witterungsunbilden auf seiner harten Aufgabe beharrt:

Steinig sei mir zu Mut

und das Tagwerk des Hirten scheine mir möglich

Frühmorgens am 19. Februar zieht Rilke sein schweres Gepäck voller Bücher hinter sich her zum Bahnhof von Ronda. In seinem Kopf hat er wahrscheinlich jene spanische Synthese, die er einige Monate später schreiben sollte: „... ungestüme Erscheinungen, verzückte Landschaften ... “.

Die Erinnerung an Ronda kommt ihm zehn Jahre später und in dem unerwartetsten Augenblick: während er die dunklen und phantastischen "Sonette an Orpheus" schreibt. Eines dieser Sonette ist ein Lied, ein leutseliges und tänzerisches Gedicht. Der Author erklärt: „Das kleine FrühlingsLied erscheint mir gleichsam als ,Auslegung' einer merkwürdig tanzenden Musik, die ich einmal von den Klosterkindern in der kleinen Nonnenkirche zu Ronda (in Süd-Spanien) zu einer Morgenmesse habe singen hören. Die Kinder, immer im Tanztakt, sangen einen mir unbekannten Text zu Triangel und Tamburin". Es ist das XXI. Sonett des ersten Teils:

Frühling ist wiedergekommen. Die Erde ist wie ein Kind, das Gedichte weiß; viele, o viele ... Für die Beschwerde langen Lernens bekommt sie den Preis.

Streng war ihr Lehrer. Wir mochten das Weiße an dem Barte des alten Manns.

Nun, wie das Grüne, das Blaue heiße, dürfen wir fragen: sie kanns, sie kanns!

Erde, die frei hat, du glückliche, spiele nun mit den Kindern. Wir wollen dich fangen, fröhliche Erde. Dem Frohsten gelingts.

O, was der Lehrer sie lehrte, das Viele, und was gedruckt steht in Wurzeln und langen schwierigen Stammen: sie singts, sie singts! 
In Madrid wohnte der Dichter im Palace Hotel; er brauchte nur auf die andere Straßenseite zu gehen, um zum Pradomuseum zu gelangen. Dies tat er mehrmals, und er betrachtete jedes Mal „El Grecos Gemälde mit Leidenschaft, Goyas mit Erstaunen und die von Velázquez mit dem größtmöglichen Respekt“. Er tat nichts anderes. Er hatte „weder Mut noch Entschluß".

Der Dichter gab die letzten Peseten für einige El Greco-Reproduktionen und die Biographie des Malers aus, die von Cossío verfaßt war und welche er, wie er sagte „las ich es spanisch, denn so unmöglich das Sprechen mir vorkommt, im Lesen tu ich schon gelegentlich“. Die Empfehlungsschreiben, die er für Cossío selbst und für einen nach Madrid abgesandten österreichischen Diplomaten mitführte, blieben in seinem Hotelzimmer und wurden von ihm wahrscheinlich bei seiner Abreise zerrissen.

Das einzige Bild, das seinen Geist erfüllte, als er am Nordbahnhof den Zug in Richtung Paris nahm, war El Grecos Christus, das er rasch zum letzten Mal einige Stunden vor seiner Abreise besucht hatte.

\section{Wie sie hätten sein können}

Jetzt müssen wir uns einige Jahre zurückversetzen: genau zehn Jahre, vor seiner Ankunft in Spanien. Als Rilke im Sommer 1902 zum ersten Mal nach Paris kam, tat er dies mit großer Bewunderung für zwei Persönlichkeiten: den Bildhauer Rodin und den spanischen Maler Ignacio Zuloaga. Rodin und Zuloaga werden zu der Zeit und in demselben Zusammenhang in verschiedenen Briefen erwähnt, die der Dichter zwischen 1902 und 1906 schrieb. Er kannte Rodin durch Clara Westhoff, die eine seiner Schülerinnen war, und Zuloaga, weil er zwei Gemälde des baskischen Malers gesehen hatte: „Die Zwergin doña Mercedes“ in Berlin und „Die Schauspielerin Consuelo" in Dresden.

Die Bewunderung, die er für das Werk von Zuloaga hegte, rief in Rilke zwei sehr lebhafte Begehren hervor: den Maler kennenzulernen und über ihn ein „kleines und schönes Buch“ zu schreiben. Er schaffte es endlich, das Studio zu betreten, das Zuloaga auf dem Montmartre hatte. Es war im Frühling 1903. Dort konnte er die drei El Grecos sehen, die im Besitz des baskischen Malers waren, sowie die unzähligen Gemälde, die Zuloaga - auf dem Gipfel des Ruhmes und der Ausstellungen - während jener Monate malte. Er kam später noch einmal anläßlich der Taufe von Zuloagas Sohn zurück. Aber es ist schmerzlich, festzustellen, daß alles, was sich auf die Beziehung zwischen Zuloaga und Rilke bezieht, in einem Ambiente des Un- 
verständnisses und der Unkenntnis verläuft. Erstens wußte der baskische Maler zu keiner Zeit, wer dieser abgemagerte, blauäugige junge Mann war, der es sich in den Kopf gesetzt hatte, über sein Werk zu schreiben. Dieser junge Mann, der mit erheblichen Schwierigkeiten französisch sprach und ihm einige Bücher mit Gedichten brachte, die es nicht wert waren, geöffnet und angesehen zu werden, da sie auf deutsch geschrieben waren. Bei der Tauffeier spielte Albéniz auf dem Klavier; dies mußte etwas Wunderbares sein, aber Rilke war sich der Größe des Augenblicks nicht bewußt: es gibt in seiner peinlich genauen Briefsammlung keinen einzigen Bezug auf die Partituren oder auf den Interpreten. Dort waren auch der Bildhauer Mateo Inurria und der Dramatiker Eduardo Marquina. Zwischen ihnen und Rilke gab es nicht mehr als ein paar Grußworte: keiner war sich bewußt, wer der andere war.

Natürlich wurde nichts aus jenem „kleinen und schönen Buch“ über das Werk von Zuloaga, das Rilke - mehrere Jahre lang - zu schreiben gedachte. Der Maler gab ihm keine Gelegenheit dazu. Aus der Beziehung zwischen Zuloaga und Rilke verbleiben jedoch zwei überraschende Gedichte. Eines ist „Corrida“, das im Deutschen denselben Titel hat und dem Stierkämpfer Francisco Montes, Paquiro, gewidmet ist, welcher derjenige war, „der zuerst das ,gallear el toro ' versuchte: das Plötzlich-sich-Abwenden von dem rasenden Tier, das, da es das Gesicht des Gegners nicht mehr findet, durch die plötzliche Veränderung verwirrt, vorbeistürzt und erst im nächsten Wenden den Stoß empfängt" - wie Rilke Clara in einem Brief vom September 1907 erklärt. In seinem ganzen Leben ist Rilke weder auf einem Stierkampfplatz gewesen, noch hat er einen Stierkampf gesehen, wobei das Gedicht jedoch den Stierkampf mit bemerkenswerter Intuition wiedergibt.

Seit er, klein beinah, aus dem Toril ausbrach, aufgescheuchten Augs und Ohrs, und den Eigensinn des Picadors und die Bänderhaken wie im Spiel hinnahm, ist die stürmische Gestalt angewachsen - sieh: zu welcher Masse, aufgehäuft aus altem schwarzen Hasse, und das Haupt zu einer Faust geballt, nicht mehr spielend gegen irgendwen, nein: die blutigen Nackenhaken hissend hinter den gefällten Hörnern, wissend und von Ewigkeit her gegen Den, der in Gold und mauver Rosaseide plötzlich umkehrt und, wie einen Schwarm 
Bienen und als ob ers eben leide, den Bestürzten unter seinem Arm durchläßt, - während seine Blicke heiß sich noch einmal heben, leichtgelenkt, und als schlüge draußen jener Kreis sich aus ihrem Glanz und Dunkel nieder und aus jedem Schlagen seiner Lider, ehe er gleichmütig, ungehässig, an sich selbst gelehnt, gelassen, lässig in die wiederhergerollte große Woge über dem verlornen Stoße seinen Degen beinah sanft versenkt.

Das zweite Gedicht ist die „Spanische Tänzerin“. Diese Tänzerin - oder besser gesagt Flamencotänzerin - ist Carmela, die Zuloaga einige Jahre zuvor gemalt hatte - „Carmen, die Zigeunerin“ -, und die, begleitet vom Gitarrespieler Palmero auf der Tauffeier von Zuloagas Sohn im Studio, das der Maler auf Montmartre hatte, einige aus Cádiz stammende Tänze aufgeführt hat.

Wie in der Hand ein Schwefelzündholz, weiß, eh es zur Flamme kommt, nach allen Seiten zuckende Zungen streckt -: beginnt im Kreis naher Beschauer hastig, hell und heiß ihr runder Tanz sich zuckend auszubreiten.

Und plötzlich ist er Flamme, ganz und gar. Mit einem: Blick entzündet sie ihr Haar und dreht auf einmal mit gewagter Kunst ihr ganzes Kleid in diese Feuersbrunst, aus welcher sich, wie Schlangen die erschrecken, die nackten Arme wach und klappernd strecken.

Und dann: als würde ihr das Feuer knapp, nimmt sie es ganz zusamm und wirft es ab sehr herrisch, mit hochmütiger Gebärde und schaut: da liegt es rasend auf der Erde und flammt noch immer und ergiebt sich nicht -. Doch sieghaft, sicher und mit einem süßen grüßenden Lächeln hebt sie ihr Gesicht Und stampft es aus mit kleinen festen Füßen.

Im Sommer 1904 und nachdem er von September 1903 bis Juni 1904 ein Studienjahr in Rom verbracht hatte, wo er mit den „Aufzeichnungen des Malte Laurids Brigge“ kämpfte, erwog der Dichter das Für und Wider verschiedener Möglichkeiten: nach Paris zurückzukehren - wo die wenigen 
Sachen waren, die ihm gehörten -, in das spanische Baskenland zu reisen, wie ihm Ignacio Zuloaga empfohlen hatte, nach Rußland zurückzukehren - obwohl der Krieg mit Japan ihm diese Möglichkeit weniger attraktiv erscheinen ließ - oder die skandinavischen Länder zu besuchen, wozu ihn seine langjährige Bewunderung für Jacobsen und seine jüngsten Lektüren von Kierkegaard antrieben.

Wenn Zuloaga ihm auch nur einen Deut Aufmerksamkeit geschenkt und ihn in sein Haus in Zumaya eingeladen hätte, dann wäre Rilke 1904 nach Spanien gereist. Aber das Dilemma, wo er hinfahren sollte, wurde durch einen Brief von Ellen Key gelöst. Die schwedische Schriftstellerin war eine der ersten Spezialisten in Bezug auf Rilkes Werk, dem sie verschiedene Essays gewidmet und die den Dichter unter den Intellektuellen ihres Landes bekannt gemacht hatte. Die Aussicht, ein Publikum zu finden, das an seinem Werk interessiert war, war für Rilke besonders attraktiv. Ellen Key bot ihm die Möglichkeit an, verschiedene Vorträge zu halten und an ruhigen Orten zu leben, die es ihm erlauben würden, in Einsamkeit zu schreiben.

Wie wir zuvor gesagt haben, hatte Rilke nach Spanien ein Empfehlungsschreiben (wir nehmen an von Zuloaga, aber das ist nicht sicher) für Manuel Bartolomé Cossío, den ersten Biographen des El Greco, mitgebracht. Aber Rilke rief ihn nicht an und zerriß das Empfehlungsschreiben wahrscheinlich als er erneut nach Paris fuhr.

Hätte Rilke Cossío kennengelernt, so wäre er zweifellos zu dessen Haus in die Obeliskenstraße gegangen, in der das „Freie Lehrinstitut“ lag, und hätte dort Francisco Giner de los Ríos kennengelernt. Cossío und Giner hätten ihn wahrscheinlich zu dem Studentenwohnheim gebracht, das kurz zuvor - im Jahre 1910 - eröffnet worden war. Und Rilke hätte sich in der bescheidenen und vergeistigten Atmosphäre der Institutsangehörigen wohl gefühlt. Er hätte vielleicht Juan Ramón Jiménez kennengelernt, der genau im Dezember 1912 mit „Platero und ich“ sowie mit ungefähr zehn weiteren unveröffentlichen Büchern unter dem Arm von Moguer nach Madrid zurückgekehrt war.

Wenn diese beiden Annäherungen an zwei spanische Persönlichkeiten Zuloaga und Cossío - ihren Höhepunkt erreicht hätten, hätte Rilke, der am Ende die spanische Sprache gut verstand, vermutlich ein Gedicht auf spanisch geschrieben. Wir hätten zwar kein Werk wie seine französischen Gedichte - fast fünfhundert -, aber vielleicht doch ein kurzes und wertvolles Werk wie seine russischen Gedichte.

Wenn wir diesen Gedanken weiterspinnen würden, könnte man sogar denken, daß Rilke ein spanischer Dichter hätte sein können. 
Sie werden sich an jenen erstaunlichen Brief erinnern, den Rilke am 5. März 1902 aus Westerwede an Alexei Suvorin sandte. Suvorin war der Direktor einer der wichtigsten russischen Zeitungen, die trotz ihres $\mathrm{Na}$ mens „Новое Время" [Neue Zeit] eine ausgesprochen konservative Zeitung war. In der Literaturgeschichte gibt es wohl kein Zeugnis größerer Entwurzelung als jenen Brief: Rilke ist bereit, seine Sprache und seine Kultur aufzugeben. Er bietet Suvorin an und begibt sich in dessen Hände für den bescheidenen Gegenwert eines Gehalts, ein russischer Schriftsteller zu werden. Es ist nicht übertrieben, zu sagen, daß das Datum dieses Briefs, der 5. März 1902, ein entscheidender Augenblick in der europäischen Literatur ist.

Der kulturelle Exodus, der Rilke in die Hände Suvorins treibt, geht von der Unbehaglichkeit aus, die Rilke - zumindest in jener Epoche - fühlt, in der sich seine Kultur, die deutsche, befindet und nicht befindet, bitteres Drama. „Ich bin ein Einsamer und Überzähliger in diesem Lande, in welchem es keine Demut gibt und keinen Gott für Schweigsame und Demütige. Und ich würde glauben, daß ich überall so einsam und verloren und überzählig wäre, wenn ich nicht zweimal (in den Jahren 1899 und 1900) in Rußland gewesen wäre, wo ich erkannte, daß es eine Heimat für mich gibt, ein Erdreich, in dem ich Wurzel schlagen, ein Volk, das ich lieben könnte das ich liebe".

Rilke ist bereit, einen Schritt zu tun, der für einen Schriftsteller schwierig vorstellbar ist: seine Sprache aufzugeben. Er sagt Suvorin: „Verknüpfen Sie mich irgendwie mit Ihrem großen und zukunftsvollem Lande, an das ich glaube mit jeder Fiber meines Gefühles“. Anschließend gibt er eine mühsame Darlegung seiner Fähigkeiten: ,in einer Stunde der Inspiration kann ich russische Verse schreiben, aus dem Unbewußten heraus“. „Ich würde mich jedenfalls in kurzer Zeit in den Stand setzen, russisch zu schreiben was ich so sehr wünsche. Ich habe schon öfters russische Briefe geschrieben, und wenn ich es in diesem Falle nicht versucht habe, so geschah's, weil ich vieles zu sagen hatte, was ich deutlicher und besser in der gewohnten Sprache sagen zu können glaubte". Und der entscheidende, nicht umkehrbare Satz seines literarischen Selbstmordes ist: „In dem Moment, wo ich diesen Schritt tue, meine deutsche Vergangenheit in Flammen aufgeht, so daß ich nicht mehr zu ihr zurückkehren kann".

Suvorin antwortete nicht. Am 28. August war Rilke bereits in Paris, in einem kleinen Hotel des Quartier Latin, in der Nummer 11 der rue Toullier. 
Man kann über eine andere Präsenz Rilkes in Spanien sprechen, die sich von jener persönlichen Präsenz im Winter Ende 1912 und Anfang 1913 unterscheidet. Es handelt sich um seine jetzige Präsenz: die Präsenz von Rilkes Werk in der spanischen Dichtung.

Der Einfluß Rilkes auf die spanischen Dichter ist sehr spät und paradox, da er erst nach dem Bürgerkrieg erfolgt, in den vierziger Jahren des letzten Jahrhunderts. Paradox, weil von den spanischen Dichtern, wenn sie gefragt würden, fast alle sagen würden, daß Rilke einer der Dichter ist, den sie am meisten bewundern, obwohl jene Dichter Rilke nicht auf deutsch lesen würden, in einer Sprache, die sie im allgemeinen nicht beherrschen, und dies außerdem gerade katholische Dichter sind, die, trotz Rilkes Kritik an der Christusfigur, aussagen, daß Rilke bedeutenden Einfluß auf ihr Werk habe.

Und hier kommen zwei Fragen auf. Erstens: Kann man den Einfluß eines Dichters erleben, wenn man diesen Dichter nicht in der Sprache gelesen hat, in der er sich ausdrückt? Zweitens: Können aus dem enormen Werk Rilkes, das so verschiedene Etappen umspannt und so unterschiedliche Werke enthält wie „Die neuen Gedichte“ und die „Duineser Elegien“ einige eigene Merkmale isoliert werden, die dann später in das Werk der spanischen Dichter hereingezogen werden können?

Wenn die Antwort auf die erste Frage negativ ist, wäre es nicht einmal erforderlich, zu versuchen, auf die zweite zu antworten. Und es gibt sicherlich Gründe dafür, auf die erste Frage negativ zu antworten: die Dichtung ist nicht übersetzbar. Rilke hat dies mit Bestimmtheit gesagt. Wenn die Übersetzung wörtlich eng an das Original angepaßt erfolgt, gehen alle wohltönenden Werte verloren. Wenn die Übersetzung versucht, die wohltönenden Werte zu vermitteln, werden diese nie dem Original entsprechen, sondern diejenigen sein, die der Übersetzer erstellt.

Wir wollen jedoch vorübergehend die erste Frage zustimmend beantworten, auf der Grundlage, daß Rilke in Spanien gute Übersetzer gehabt hat. Zur Beantwortung der zweiten Frage müßten die Merkmale präzisiert werden, die Rilkes Dichtung am meisten auszeichnen.

Das Charakteristische bei Rilke ist nicht die ständige Behandlung der großen Themen - die Natur, die Zeit und der Tod -, weil jene Themen zu jeder Zeit in der Dichtung präsent sind. Auch nicht die Wiederholung seiner bevorzugten Symbole: der Engel, der Held, das Kind, die Rose, die Fontäne, die Waage, das Fenster, der Spiegel. 
Das Charakteristische bei Rilke ist, daß er ständig die Kehrseite der Realität wahrnimmt, „die andere Seite der Natur“. Rilke verbleibt nicht auf der sichtbaren Rückseite. Sein Blick umfaßt die beiden Seiten: die sichtbare und die unsichtbare. Und er hört die Resonanz der einen und der anderen in der eigenen Intimität. Man könnte sagen, daß seine Gedichte drei Elemente enthalten: sichtbare Realität, unsichtbare Realität und eigene intime Resonanz. Und das Gedicht als solches ist für Rilke ein Ding, „ein Meteor“, wie er in der "Spanischen Trilogie“ sagt.

Das Ding zu machen, Herr Herr Herr, das Ding,

welthaft-irdisch wie ein Meteor,

ein Ding, das außerordentlich präzise sein muß. „Er war ein Dichter und haßte das Ungefähre“, wird von einer der Figuren in den „Aufzeichnungen des Malte Laurids Brigge" gesagt, und so konkrekt und fest wie in den Werken, die mit den Händen erschaffen wurden, wie die Seile, die Rilke einen Seiler in Rom flechten sah, oder die Gefäße, die er einen Töpfer am Nil herstellen sah und an die sich der Dichter in der "Neunten Elegie“ erinnert.

Der Gedanke, daß die Dinge eine Melodie hervorbringen oder einen „Klang" oder eine „Stimme“ oder eine „Musik“, ist der Schwerpunkt von Rilkes Dichtung und wird bereits in den frühen Texten ausgedrückt. Nur wenn sich der Dichter „Lauschen und Staunen“ hingibt, kann er diese Melodie begreifen und in ein Lied umwandeln. Auch der Gedanke des Gedichts als Lied ist in seinem gesamten Werk präsent und hat sehr zahlreiche Kompositionen veranlaßt. „Die Dinge singen hör ich so gern“ sagt ein Vers des „Stundenbuches“. Und in einem im Januar 1898 verfaßten Gedicht schrieb Rilke:

Vor lauter Lauschen und Staunen sei still,

du mein tieftiefes Leben;

daß du weißt, was der Wind dir will,

eh noch die Birken beben.

Und wenn dir einmal das Schweigen sprach,

laß deine Sinne besiegen.

Jedem Hauche gieb dich, gieb nach,

er wird dich lieben und wiegen.

Und dann meine Seele sei weit, sei weit,

daß dir das Leben gelinge,

breite dich wie ein Federkleid

über die sinnenden Dinge. 
Im Winter 1898 sagte Rilke bei einem Vortrag in Prag: „Kunst erscheint mir als das Bestreben eines Einzelnen, über das Enge und Dunkle hin, eine Verständigung zu finden mit allen Dingen, mit den kleinsten, wie mit den größten, und in solchen beständigen Zwiegesprächen näher zu kommen zu den letzten leisen Quellen alles Lebens. Die Geheimnisse der Dinge verschmelzen in seinem Innern mit seinen eigenen tiefsten Empfindungen und werden ihm, so als es eigene Sehnsüchte wären, laut“.

Um Rilkes Einfluß auf die spanischen Dichter festzustellen, müßte ermittelt werden, bei welchen dieser Dichter gleichzeitig jene drei Elementesichtbare Realität, unsichtbare Realität und intime Resonanz - vorhanden sind, sowie außerdem, ob das Gedicht in sich selbst ein „Ding“ ist, welches mit größter Präzision und höchster Genauigkeit ausgestattet ist.

Aber eine solche Aufgabe ist offensichtlich naiv, weil die Dichtung nicht auf ein Schema beschränkt werden kann, sondern einen bestimmten Ton hat. Und wie der spanische Dicher Antonio Colinas geschrieben hat, Rilkes „flexibler, nachdenklicher und anscheinend kalter Ton, jedoch mit einem ausgezeichnenten lyrischen Inhalt", ist weit vom Ton der spanischen Dichter entfernt, die „mehr Leidenschaften und Brüchen unterworfen sind und selten Intimisten im tiefsten Sinne sind“.

Um Rilkes Präsenz bei den spanischen Dichtern zu entdecken, werde ich mich nicht an externe Ermittlungen, sondern an ihre eigene Aussagen halten: diejenigen, die Rilkes Einfluß zugegeben haben, diejenigen, die ihn übersetzt und studiert oder zitiert haben.

Von den Dichtern, die die Generation von 1927 bilden, hat Luis Cernuda die kategorischste Erklärung über die Verbindung zu Rilke abgegeben: „Der kurze Aufenthalt Rilkes in Sevilla, mein physisches Zusammentreffen mit dem Dichter, dessen Name und Werk ich erst Jahre später kennenlernte, dieselbe Luft wie er damals zu atmen, und vielleicht, warum nicht?, dem Unbekannten auf der Straße zu begegnen, ruft in mir, wenn immer ich daran denke, keine geringe Emotion hervor; da Rilkes Werk für denjenigen, der dieses schreibt, eine dieser sehr tiefen Beziehungen, einen jener Anreize darstellen, die uns um so lieber und notwendiger sind, desto

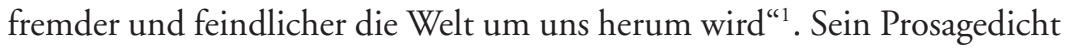
„Panther" - vom Buch „Ocnos" - ist fast eine Bearbeitung des Gedichts „Der Panther" ${ }^{\text {: }}$

Luis Cernuda, Poesía y literatura, Prosa I, B. II, S. 583.

2 Dieser ungewöhnliche Bearbeitungsfall, in dem der spanische Dichter den deutschen Dichter nicht zitiert, hat das Interesse der Kritiker erweckt: Isabel Paraíso de Leal, „Rilke y Cernuda: fuente y afinidad“, en Castilla. Estudios de literatura, Nr. 1, 1980, S. 71; Gemma Suñé Min- 
Seine schlanke, samtartige Schwärze, die kein anderes Gewicht zu haben scheint als das hinlängliche, um sich der Luft mit eigenem Widerstand entgegenzustellen, geht und kommt eintönig hinter den Eisen, vor denen, die verführt von solcher unheilvollen Schönheit dort verweilen, um sie zu betrachten. Die materielle Kraft wird dort als beherrschende Grazie benutzt, und der Wille gestaltet, wie beim Tänzer, ein perfektes körperliches Gleichgewicht, jeder Muskel genau und flügelartig angeordnet ist, dem nach dem mathematischen und musikalischen Vorbild nach, das seinen Bewegungen Gestalt gibt.

Nein, weder Basalt noch Granit könnten ihn gestalten, aber doch ganz allein ein Stückchen Nacht. Luftig und leicht wie die Nacht selbst, ebenso großartig und düster wie das Ganze, von dem aus irgendein welterschütterndes Ereignis sie auf die Erde herunterwarf, diese Schwärze wird durch das graugrüne Licht der Augen erleuchtet, in denen manchmal deren Zerreiß- und Zermalmdrang zum Vorschein kommt, der einzige Gedanke zwischen der geistigen Masse seiner Langeweile. Welcher Dichter oder welcher Teufel haßte derart und so stark die umgebende menschliche Alltäglichkeit?

Und wenn jener Blitz erlöscht, mit Rücksicht dann auf eine andere Realität, die die Sinne nicht deutlich sehen, bleibt sein Blick teilnahmslos angesichts der angriffslustigen äußeren kränkenden Gespenstigkeit. So unterdrückt flüchtet seine zerstörerische Kraft über die Erscheinungsform hinaus, und jene Erscheinungsform, die seine Augen nicht sehen, oder nicht sehen wollen, unmittelbar, aber unerreichbar für den Fang, zerstört der tierische Gedankengang jetzt ohne Blut, besser und vollständiger.

Luis Rosales und Luis Felipe Vivanco sind die Dichter der ersten Nachkriegsgeneration, die zugeben, von Rilke beeinflußt zu sein. Luis Rosales sagte es deutlich: „Ich glaube, daß ich einer der Schriftsteller bin, auf den Rilke in Spanien den größten Einfluß hat oder gehabt hat “" . Dieses Gedicht, „Gestern wird kommen“, stammt aus seinem Buch „Reime“:

Der Abend wird sterben. Auf dem Weg

löst sich die Blüte der Akazien

durch den Schwung des Windes auf. Zwischen den Zweigen,

untrüglich, fast schwungvoll,

verbleibt die letzte Sonne. Die Erde riecht,

fängt zu riechen an, paßt nicht

in sich selbst und erhebt sich:

jetzt gibt es Erde in der Erde und in der Luft.

Und es gibt eine Dornenhecke mit Sonne; bis dorthin gelangen wir;

der Schatten ist der Inbegriff des Abends.

Ich habe dich weinen gefühlt. Ich weiß nicht, für wen du weinst.

Es gibt einen weitentfernten Rauch,

ein Zug, der vielleicht zurückkehrt, während du sagst:

Ich bin dein eigener Schmerz. Laß mich dich lieben.

guella, „Reescribiendo a Rilke. La pantera de Luis Cernuda“, Cuadernos hispanoamericanos, $\mathrm{Nr}$. 625-626, 2002, S. 41.

3 Luis Rosales, „Autobiografía literaria improvisada ante un magnetófono“, in Obras Completas, B. VI, Madrid 1998, S. 286. 
Luis Felipe Vivanco übersetzte „Das Stundenbuch“. In Wirklichkeit war es seine Frau, damals seine Verlobte, María Luisa Gefaell, die eine erste wörtliche Version des Deutschen erstellte, und Vivanco verwandelte diese Texte in spanische Gedichte. Genauso verfuhren Gonzalo Torrente Ballester und Mechthild von Hesse Podewils. Sie verfaßte eine erste spanische Version der „Duineser Elegien“, die dann von Torrente Ballester bearbeitet wurde ${ }^{4}$. Die Übersetzung von Rilke bedeutete für Vivanco außerdem „eine entscheidende Aufklärung “5 in der Entwicklung seines dichterischen Werkes. Es gibt zwei Bücher Vivancos, in denen Rilkes Einfluß am sichtbarsten ist: „Die Wege“ - geschrieben in den vierziger Jahren und bis 1974 nicht veröffentlicht - und „Das freie Feld“ - veröffentlicht 1957.

Die Dichter aus der zweiten Nachkriegsgeneration, die Rilke am nächsten stehen, - ich würde nicht sagen, die am meisten von dem deutschen Dichter beinflußt sind -, sind José María Valverde und José Ángel Valente. Valverde ist der größte Rilkeübersetzer in Spanien gewesen, und ich benutze dieses Adjektiv sowohl für die Menge als auch die Qualität. Aber obwohl es üblich ist, einen Einfluß Rilkes auf Valverde zu behaupten, glaube ich, daß dieser Einfluß sehr gering ist, da der manchmal lehrhafte und manchmal ironische Ton Valverdes wenig mit Rilke und viel mehr mit Brecht zu tun hat. Man könnte auf jeden Fall sagen, daß ein gewisser anfänglicher Einfluß Rilkes immer mehr und sehr bald verschwimmt.

José Ángel Valente, der sehr scharfsinnige Seiten über Rilke geschrieben hat -, Rainer Maria Rilke: der Raum der Offenbarung “6 - enthüllt keinen Einfluß des deutschen Dichters. Sein Ton, mit fortschreitender Entpersönlichung sowie fortschreitender verbaler Nüchternheit, hat nichts mit Rilke zu tun. „Das dichterische Wort - schrieb Valente - lädt uns ein, in einen

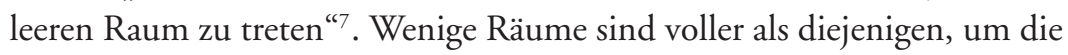
es hier geht, - im Gegenteil -: die Gedichte des deutschen Dichters.

Unter den großen lebenden Dichtern ist Antonio Colinas zweifellos derjenige, der Rilke am nächsten ist. Im Verlauf des Lebens des einen und des anderen besteht eine bedingungslose Hingabe an die dichterischen Aufgabe. Ich sage nicht, wie es üblicher Gemeinplatz ist, daß darin Leben und Werk eine „unspaltbare Einheit“ bilden, sondern etwas vielleicht $\mathrm{Zu}$ verlässigeres: daß sie eine verflochtene Zweiheit bilden. Sie widmen ihr Leben dem Werk, und das Werk gibt ihnen eine größere und scharfsinnige-

\footnotetext{
Gonzalo Torrente Ballester, „Las Elegías de Duino“, Madrid 1946.

José Ángel Fernández Roca, „La palabra vivida. Aproximación a Luis Felipe Vivanco y su poesía", in Luis Felipe Vivanco, Obras I, Poesía I, Madrid 2001, S. 28.

José Ángel Valente, Las palabras de la tribu, Madrid 1994, S. 215.

José Ángel Valente, Poesia en la Residencia, Madrid 2001, S. 17.
} 
re Fähigkeit zurück, das Leben wahrzunehmen. Weder Colinas noch Rilke sind von den Umständen abhängige Schriftsteller: die Gedichte keimen in ihnen aus jener „unendlichen Geduld“, die Rilke dem "Jungen Dichter" empfahl, aus einem langsamen Reifungsprozeß in der Einsamkeit. „Weder der eine noch der andere haben einen Verskünstlerdrang, eine leere Phantasielosigkeit oder einen Laborexperimentalismus".

Colinas hat nicht nur über Rilkes Werk nachgedacht, sondern dieses auch über aufeinanderfolgende Wiederlesungen in sein eigenes Werk eingegliedert ${ }^{9}$. Die poetische Sprache Colinas hätte ohne Rilkes Einfluß dieselben Pracht- und Wahrheitsbestandteile ${ }^{10}$, die die Verse des deutschen Dichter charakterisieren, aber es ist möglich, daß damit diese selben Züge sich in Colinas Werk verschärfen. In beiden poetischen Werken empfindet man dieselbe „Harmonie orphischen Ursprungs ${ }^{\text {" }}{ }^{11}$ : vielleicht durch Rilkes Einfluß verstärkt und bereinigt bei Colinas.

Die Annäherung oder das Zusammenlaufen von poetischen Tönen des einen und des anderen zeigt sich insbesondere in jenen Gedichten von Colinas, in denen dieser entweder Gedichte von Rilke umarbeitet - „Variationen über zwei Rilkethemen " - oder sich in den Schatten der Verse des deutschen Dichters stellt bzw. diesen zitiert, manchmal in langen Gedichten wie „Das schwarze Grab“ oder in ganzen Büchern wie „Zeit und Abgrund“.

Und ich schließe mit der Lesung eines Gedichtes von Colinas ab, in dem dieser den letzten Auftritt Rilkes auf dieser Erde ins Gedächtnis ruft, Augenblicke, bevor Rilke unter derselben auf dem kleinen Alpenfriedhof von Raron lag. Ich weiß nicht, ob es in diesem Gedicht eine sichtbare Analogie zwischen den Versen beider Dichter gibt, aber es besteht auf jeden Fall derselbe Scharfsinn, und in dem Gedicht kommt auf jeden Fall Colinas Verehrung für den deutschen Dichter zum Ausdruck. Der Titel des Gedichtes lautet „Die Cellospielerin Alma Moodi interpretiert Bach bei Rilkes Totenfeier":

Nichts bedeuten die Verse und die Musik.

Nichts bedeutet der Ruhm.

Nichts bedeutet der Tod des Dichters, jeder Tod.

Gewiß ist nur jener Frauenkörper, der verzweifelt retten will,

mit der Musik von Bach jene andere

\footnotetext{
8 Antonio Colinas, El sentido primero de la palabra poética, S. 158

9 Ebenda, S. 163.

10 Ebenda, S. 137.

11 Ebenda, S. 163.
} 
Verse die Jemand (erscheint uns)

zum Schweigen bringen will, wenn ein Dichter stirbt.

Es bedeutet nur etwas jener Körper,

den die durch die Tränen getrübten Augen betrachten, und die Arme (so weiß)

die mit der Musik spielen, die vergessen lassen

die Verse, und die spielen mit den Lebenden,

um eine Zeit zu verewigen, die wir wissen

ist vergänglich, und die ihrerseits spielt

mit dem Tod.

Verse, Musik, Spiele

der Seele gleiten das Fleisch hinab,

das noch liebt und noch träumt und noch singt, ohne schon zu sterben. 